\title{
Why Great Britain's success in Beijing could have been anticipated and why it should continue beyond 2012
}

\author{
A M Nevill, ${ }^{1}$ N J Balmer, ${ }^{2}$ E M Winter ${ }^{3}$
}

${ }^{1}$ Research Institute of Healthcare Sciences, University of Wolverhampton, Walsall, UK:

${ }^{2}$ Research Institute for Sport and Exercise Sciences, Liverpool John Moores University, Liverpool, UK; ${ }^{3}$ The Centre for Sport and Exercise Science, Sheffield Hallam University, Sheffield, UK

Correspondence to: Professor A M Nevill, University of Wolverhampton, Research Institute of Healthcare Sciences, Walsall Campus, Gorway Road, Walsall WS1 3BD, UK; a.m nevill@wlv.ac.uk

Accepted 6 February 2009 Published Online First 21 May 2009

\begin{abstract}
Background: Home advantage in the summer Olympic Games is well known. What is not so well known is that countries that host the Olympic Games perform better in the games before and after the games in which they were hosts.

Objective: To model/quantify the significance associated with these "hosting" effects and to explain the likely causes of Great Britain's improved medals haul in Beijing, while examining implications for London 2012 and beyond.

Results: Using all hosting cities/countries since World War II and analysing the number of medals awarded to competitors as a binomial proportion (p) response variable within a logit model, we identified a significant increase in the probability/odds of a country obtaining a medal in the Olympic Games before, during and after hosting the Olympics.
\end{abstract}

Conclusions: Funding appears to be an important factor when explaining these findings. Almost all countries that have been awarded the games after World War II would appear to have invested heavily in sport before being awarded the games. A second factor in Great Britain's success is the legacy of hosting the Commonwealth Games in 2002 (a post-hosting games effect) that undoubtedly provided an infrastructure that benefited, in particular, cycling. Whether the International Olympics Committee either consciously or subconsciously take these factors into account is unclear when awarding the games to a city. What is clear is that based on these findings, Great Britain's prospects of maintaining the Olympic success achieved in Beijing is likely to continue to London 2012 and beyond.

Home advantage in the summer Olympic Games is well known. ${ }^{1}$ Some of the reasons for this have also been documented. For example, Balmer et $a l^{2}$ reported a marked home advantage in events that were either subjectively judged (eg, boxing, gymnastics) or relied on subjective decisions (team games), suggesting the role of officiating in increasing the medal-winning capacity of hosting nations. In contrast, little or no home advantage was observed in sports that were objectively judged (eg, athletics and weightlifting). What is not so well known is that countries that host the Olympic Games perform better in the games before and after the games in which they were hosts. Although some studies have reported a greater number of medals won in the games immediately before and after hosting the games, ${ }^{1}$ no attempt appears to have been made to quantify/model the significance associated with these improvements, nor to explain the cause of these related "home advantage" effects.

The purpose of this paper is thus to model and assess the significance associated with these effects and speculate on the possible causes of the improved medals haul in the Games immediately before and in the games immediately after hosting the Olympic Games. Findings are interpreted in the light of Great Britain's recent success in the Beijing Olympics, while considering the implications for London 2012 and beyond.

\section{METHODS}

As the data used in this study were in the public domain (obtained from the internet) and did not involve measurements of humans, ethics committee approval and informed consent was not required.

The majority of pre-World War II Olympic Games had few limits on the maximum number of competitors that could be entered, leading to inflated home-team sizes, or even additional teams in some early team games (eg, football in 1904 in which the USA claimed silver and bronze). ${ }^{2}$ For this reason, we have included only data from postWorld War II Olympic Games, in which such anomalies have been removed. All cities/countries that have hosted the Olympic Games since World War II are listed in table 1.

\section{Statistical methods}

The number of medals awarded to competitors from each country was analysed as a binomial proportion (p) as the response variable (eg, in 2008 Great Britain was awarded 47 medals out of a total of 958 available, ie, $p=47 / 958=0.049$ ) using a logit regression model. The logit model estimates the probability ( $p$ ) or odds of an event, in this case winning a medal, as follows:

$$
p=\exp (y) /[1+\exp (y)](1)
$$

where $y$ is a linear combination of the predictor variables, known as the "logit" model, given by $y=\log _{e}(p /(1-p))=$ Intercept $+B_{i} X_{i}$. Note that the "Intercept" parameter can vary between levels of a fixed factor (eg, countries) and the $\mathrm{B}_{\mathrm{i}} \mathrm{S}$ are the slope parameter(s) of one or more explanatory covariate $(\mathrm{s}) \mathrm{X}_{\mathrm{i}}$.

\section{RESULTS}

All details for the number of medals won by the post-World War II hosting countries were available and were down-loaded from the following website: 
Table 1 Total number of medals awarded by the countries hosting the Olympic Games after World War II

\begin{tabular}{llll}
\hline Hosting country & Host city & Year & $\begin{array}{l}\text { No of medals } \\
\text { awarded }\end{array}$ \\
\hline Great Britain & London & 1948 & 411 \\
Finland & Helsinki & 1952 & 459 \\
Australia & Melbourne & 1956 & 470 \\
Italy & Rome & 1960 & 461 \\
Japan & Tokyo & 1964 & 507 \\
Mexico & Mexico City & 1968 & 527 \\
Germany & Munich & 1972 & 610 \\
Canada & Montreal & 1976 & 613 \\
USSR/Russia & Moscow & 1980 & 631 \\
USA & Los Angeles & 1984 & 689 \\
Korea & Seoul & 1988 & 738 \\
Spain & Barcelona & 1992 & 815 \\
USA & Atlanta & 1996 & 842 \\
Australia & Sydney & 2000 & 927 \\
Greece & Athens & 2004 & 929 \\
China & Beijing & 2008 & 958 \\
\hline
\end{tabular}

http://www.mapsofworld.com/olympic-trivia/olympic-gamesresults/medals-by-country.html and are summarised in table 2 .

For these data, the logit model was found to be:

$$
\begin{aligned}
& y=\text { Intercept }+0.277 \text { [pre-host }]+0.718 \text { [host }]+0.381 \\
& {[\text { post-host }](2)}
\end{aligned}
$$

where the "Intercept" parameters varied significantly between the 14 host countries while not hosting the games (see table 3) and the $\mathrm{B}_{\mathrm{i}}$ slope parameters quantify the additional probability/ odds of obtaining a medal in the Olympic Games before hosting, $\mathrm{B}_{1}=0.277$ (95\% CI 0.187 to 0.366 ), while hosting, $\mathrm{B}_{2}=0.718$ (95\% CI 0.641 to 0.796$)$ and after hosting the games $B_{3}=0.381$ (95\% CI 0.294 to 0.468 ).

In the case of the medals won by Great Britain in Beijing, the logit model (Eq 2) becomes $y=-3.42+0.277$ [pre-hosting] $=-3.15$. Therefore, the probability of Great Britain winning a medal is given by $p=\exp (-3.15) /$ $[1+\exp (-3.15)]=0.0410$. Given that in Beijing, a total of 958 medals was awarded, the model predicts that Great Britain will win $958^{*} 0.0410=39$ medals. In reality Great Britain did better than that predicted, winning 47 medals in all. Nevertheless, the model anticipated an improvement in medals won, considerably better than the 28 and 30 medals won by Great Britain in Sydney and Athens, respectively.

We can use the same model to predict the probability of Great Britain winning medals when hosting the Olympics in 2012. Based on the above logit model we obtain $y=-3.42+0.718$ [hosting] $=-2.702$, and thus the probability of winning an olympic medal in London 2012 is given by (see Eq 1) $\mathrm{p}=\exp (-2.702) /[1+\exp (-2.702)]=0.0671 /[1+0.0671]$

$=0.063$. Assuming that there will be approximately 1000 medals available in 2012, it can be anticipated that Great Britain will win approximately 63 olympic medals.

Similarly, we can predict the number of medals that China might win in London 2012 (post-hosting the Beijing Olympics). The probability of China winning an olympic medal in London 2012 becomes $p=\exp (-2.47) /[1+\exp (-2.47)]=0.0847 /$ $[1+0.0847]=0.078$. Again assuming that there will be approximately 1000 medals available in London 2012, China could anticipate winning 78 of these. British sports fans should also anticipate continued success in 2016, not dissimilar to that achieved at the recent Beijing Olympics. Based on the model parameters and the assumption of approximately 1000 medals on offer, Great Britain should win approximately 46 olympic medals $(p=\exp (-3.04) /[1+\exp (-3.04)]=0.046)$.

Table 2 Mean medals won by post-World War II hosting countries, when (1) not hosting, (2) pre-hosting, (3) hosting and (4) in the games after hosting the Olympics

\begin{tabular}{lllllllllll}
\hline Country & Not hosting & $\mathbf{N}$ & Pre-hosting & $\mathbf{N}$ & Hosting & $\mathbf{N}$ & Post-hosting & N & All & N \\
\hline Australia & 19 & 10 & 26 & 2 & 46.5 & 2 & 35.5 & 2 & 25.4 & 16 \\
Canada & 9.7 & 12 & 5 & 1 & 11 & 1 & 44 & 1 & 11.7 & 15 \\
China & 44.6 & 5 & 63 & 1 & 100 & 1 & & 0 & 55.1 & 7 \\
Finland & 5.5 & 13 & 20 & 1 & 22 & 1 & 15 & 1 & 8 & 16 \\
Germany & 63.4 & 12 & 51 & 1 & 106 & 1 & 129 & 1 & 69.8 & 15 \\
Great Britain & 21.6 & 13 & 47 & 1 & 23 & 1 & 11 & 1 & 22.6 & 16 \\
Greece & 2.3 & 9 & 13 & 1 & 16 & 1 & 4 & 1 & 4.5 & 12 \\
Italy & 23.4 & 13 & 25 & 1 & 36 & 1 & 27 & 1 & 24.5 & 16 \\
Japan & 22.2 & 11 & 18 & 1 & 29 & 1 & 25 & 1 & 22.6 & 14 \\
Korea & 13.8 & 12 & 19 & 1 & 33 & 1 & 38 & 1 & 17.1 & 15 \\
Mexico & 2.9 & 13 & 1 & 1 & 9 & 1 & 1 & 1 & 3.1 & 16 \\
Spain & 6.5 & 10 & 4 & 1 & 22 & 1 & 17 & 1 & 8.3 & 13 \\
USA & 89.9 & 9 & 101 & 2 & 137.5 & 2 & 95.5 & 2 & 98.5 & 15 \\
USSR/Russia & 89.6 & 11 & 125 & 1 & 195 & 1 & 132 & 1 & 102.6 & 14 \\
All & 27.9 & 153 & 40.3 & 16 & 60.6 & 16 & 47 & 15 & 33.0 & 200 \\
\hline
\end{tabular}


Table 3 Intercept parameters of countries when not hosting (nor directly before or after hosting) the Olympic Games, estimated for the logit model regression analysis

\begin{tabular}{ll}
\hline Hosting country & Intercepts \\
\hline Australia & -3.43 \\
Canada & -4.13 \\
China & -2.85 \\
Finland & -4.48 \\
Germany & -2.26 \\
Great Britain & -3.42 \\
Greece & -5.24 \\
Italy & -3.34 \\
Japan & -3.46 \\
Korea & -3.78 \\
Mexico & -5.46 \\
Spain & -4.57 \\
USA & -1.99 \\
USSR/Russia & -1.83 \\
\hline
\end{tabular}

\section{DISCUSSION}

The British media and sports fans alike appear to have been surprised at the number of medals Great Britain won at the Beijing Olympics. Based on the logit model, we could have anticipated an increase of approximately 10 medals over and above those achieved in Sydney and Athens, an increase from approximately 30 to 40 medals. In reality, Great Britain won 47 medals, which exceeded the logit models "expectation".

However, this remarkable success could have been anticipated due to a number of contributory factors, the first being the exponential rise in funding for Great Britain sport over the past two decades. Formal support was introduced in 1988 through the Sports Science Education Programme (SSEP). This was operated under the aegis of the UK Sports Council. Between 1988 and 1998, a modest $£ 4$ million was invested in sport, providing only $£ 0.4$ million per year. In 1997, the National Lottery was introduced to support various good causes including sport; funds that were administered by UK Sport that replaced the SSEP. In the same year as the introduction of lottery funding, UK Sport introduced the World Class Performance Programme, which now administers athletes with realistic hopes of olympic medals. From May 1997 until the Sydney Olympic Games in 2000, £58.9 million was used specifically to support 13 sports. ${ }^{3}$ In the 4 years before the Athens Games of 2004, £70 million was invested to support 16 sports, and from 2004 to 2008, a further £235 million was used to support 27 sports up to the Olympic Games in Beijing. In November 2008, the UK Government announced a sum of $£ 550$ million to support 30 sports up to the London 2012 Games. Throughout these periods, approximately $15 \%$ has been used to provide scientific and medical support, which represents approximately £20 million per year to 2012 and a 50-fold increase since 1988 .

There can be little doubt that such financial support has been influential in increasing the medals won by Great Britain even before hosting the Olympics. There is also evidence that other countries/cities that were awarded the games made similar investments in sport before hosting the Olympic Games, for example, Barcelona 1992, Sydney 2000, and most recently, Beijing 2008.

The second contributory factor to Great Britain's remarkable success in Beijing is the legacy of hosting the Commonwealth Games in Manchester 2002, a benefit identified as the "posthosting" Games effect. The Games provided new facilities for athletics, tennis and squash, but probably the sport that benefited the most from the infrastructure was cycling, with the building of the national cycling velodrome. This has led to British cycling becoming a dominant force in world track cycling. The facilities and experience gained has contributed to Great Britain winning eight cycling gold medals in the Beijing Olympics as well as the remarkable success Great Britain enjoyed in the track cycling world championships earlier in 2008.

Of course, the analysis presented above is a simple approach to modelling Olympic performance and other studies have integrated a greater range of factors. ${ }^{45}$ Nonetheless, we show evidence of a marked home advantage, which importantly extends to Olympics that immediately precede and follow home Olympics. Olympics Minister, Tessa Jowell, recently suggested with the benefit of hindsight and in the light of current economic circumstances ${ }^{6}$ that Britain might not have bid for the Olympics, and debates continue about funding arrangements both for athletes ${ }^{7}$ and venues ${ }^{8}$ in the light of the global financial crisis. Despite this, Olympic Delivery Authority Chief Executive, Dave Higgins, has recently attempted to set out benefits of the Olympics in terms both of job creation and the long-term regeneration of East London. ${ }^{9}$ The present study adds to this debate, by highlighting not only the potential increased medal winning in 2012, but also predicting ongoing sporting success (in 2016) that should, all being well, outlast the current financial situation.

Competing interests: None.

\section{REFERENCES}

1. Clarke SR. Home advantage in the Olympic Games. Proceedings of the Fifth Australian Conference on Mathematics and Computers in Sport. 14-16 June 2000, Sydney, Australia. Cohen G, Langtry T, eds. Sydney, NSW: University of Technology Sydney, 2000:43-51.

2. Balmer NJ, Nevill AM, Williams AM. Modelling home advantage in the Summer Olympic Games. J Sport Sci 2003;21:469-78.

3. UK Sport. Summer Olympic sports. http://www.uksport.gov.uk/pages/ summer_olympic_sports_-_home/ (accessed March 2009).

4. Andreff $\mathbf{M}$, Andreff $\mathbf{W}$, Poupaux S. Economic determinants of the Olympic performance: forecasts of the medals to be won at Beijing Olympics Games. Revue D'Economie Politique 2008;118:135-69.

5. Condon EM, Golden BL, Wasil EA. Predicting the success of nations at the Summer Olympics using neural networks. Computers Operations Res 1999;26:1243-65.

6. Telegraph.co.uk. Tessa Jowell: Britain would not have bid for 2012 Olympics if we knew about recession. 12 November 2008. http://www.telegraph.co.uk/sport/ othersports/olympics/london2012/3448188/Tessa-Jowell-Britain-would-not-have-bidfor-2012-Olympics-if--we-knew-about-recession.html (accessed March 2009).

7. BBC. Jowell rejects athlete cash fears. 22 August 2008. http://news.bbc.co.uk/2/hi/ uk news/politics/7576183.stm (accessed March 2009).

8. Telegraph.co.uk. Financial crisis ensures London 2012 facing chilly review. 18 November 2008. http://www.telegraph.co.uk/sport/othersports/olympics/london2012/ 3479832/Financial-crisis-ensures-London-2012-facing-chilly-review-London-2012.html (accessed March 2009).

9. London 2012 Olympics. Games are already delivering a 'shot in the arm for UK plc' says Higgins. 4 December 2008. http://www.london2012.com/news/media-releases/ 2008-12/games-are-already-delivering-a-shot-in-the-arm-for-uk-plc-says-higgins.php (accessed March 2009). 